\title{
The grandchildren of patients with pyloric stenosis
}

\author{
C O CARTER, KATHLEEN EVANS, AND JOAN WARREN
}

From the MRC Clinical Genetics Unit, Institute of Child Health, London WCIN IEH.

SUMMARY Of 138 grandchildren of patients, four had pyloric stenosis confirmed at Ramstedt's operation. For the four categories of grandchildren of male index patients the proportion affected was $0 / 27,1 / 17,1 / 41$, and $0 / 35$ for sons' sons, sons' daughters, daughters' sons, and daughters' daughters, respectively. For the four categories of grandchildren of female index patients the proportion affected was $0 / 5,1 / 3,0 / 5$, and $1 / 5$, respectively. Though numbers are small certain findings are noteworthy. The relatively high risk to the relatives of female index patients appears even more marked in the grandchildren than the children. The grandchildren of male index patients show the sharp decrease in proportion affected that one would expect with a multifactorial threshold model, but of the few grandchildren born so far to female index patients, as many are affected as the children. In only one of the four instances was the affected grandchild born to an affected child. There is no support for the hypothesis that the higher risk to the children of female index patients is the result of a direct maternal effect on the developing fetus.

Information on the proportion affected of grandchildren of patients with pyloric stenosis adds to the pattern of familial incidence of the disorder for a major class of second degree relatives. It also provides a further test of hypotheses to explain the high male preponderance of patients with the disorder.

In 1969 , two of the authors ${ }^{1}$ described the family patterns of congenital pyloric stenosis based on a large and consecutive series of patients, who were the adult survivors of early Ramstedt's operation performed at The Hospital for Sick Children, London. The study gave estimates of the risks to sibs, children, nephews, and nieces of a large series of index patients. But at that time no grandchildren had been born. A striking finding in the children was that, whereas pyloric stenosis developed in about $5 \frac{1}{2} \%$ of the sons and $2 \frac{1}{2} \%$ of the daughters of male patients, for female patients the figures were some three times higher, $19 \%$ for sons and $7 \%$ for daughters. The proportions were approximately 10 , 25,40 , and 70 times the incidence in the general population of the same sex. A similar, if less marked, effect of sex of index patients is seen in sibs, the percentage affected being about 4 and $2 \frac{1}{2}$ for brothers and sisters of male index patients, and 9 and 4 for brothers and sisters of female index patients.

We thought that the most plausible explanation of these findings was a multifactorial threshold model Received for publication 21 February 1980 with girls protected by their sex, such that their threshold deviated substantially more from the population mean than did the threshold for boys; that is to say, girls required a stronger genetic predisposition to develop the disorder than did boys. An alternative ${ }^{2}{ }^{3}$ or supplementary ${ }^{4}$ hypothesis is that the female patient, when adult, has a direct environmental effect on her fetus in utero contributing to the development of the condition. Such a mechanism might help to explain a higher risk to the children of female than male patients, but also might be expected to give a higher risk to the brothers and sisters of patients than of children, since presumably this effect is strongest in the mothers of patients with the disorder, rather than in the female patients themselves.

\section{Material and methods}

The authors went back to the original series of patients $^{1}$ whom they had visited in their homes before 1968 and attempted to get in touch with 180 male (a further three who were known to be abroad and three who would probably have found the visit disturbing were excluded) and 45 female index patients who were found at the home visit to have had children before 1960 and so might have grandchildren. To trace the index patients, a letter was sent first to the address which we had in 1967. If this failed, an attempt was made to trace the patient's 
doctor through the National Health Service Central Register at Southport and the Family Practitioner Committee and then the patient through the family doctor. If this failed and sufficient details of a child of the patient were available an attempt was made to find the child through his doctor via the Central Register. Of the 180 men, 163 were traced: 104 through their last address, 54 through Southport, and five through a child and Southport. Of the 45 women, 34 were traced, 28 through their last address, four through Southport, and four through a child and Southport. There were 13 men and eight women who were not traced; a further four men and three women were abroad. A letter was sent to the 163 men and 34 women asking how many grandchildren they had. Where grandchildren had been born questions were asked by telephone about early weight gains and any vomiting, or by postal questionnaire to the few families who had no telephone. Histories suggestive of pyloric stenosis were checked by reference to the family doctor and hospital reports were obtained where there had been an operation in infancy. A grandchild was considered affected only if the diagnosis of pyloric stenosis had been confirmed at Ramstedt's operation. Once traced, only one man and no woman was not willing to supply information. All the grandchildren were at least 3 months of age and so past the period at risk at the time the study was closed in June 1979.

We think it unlikely that failure to trace has introduced any bias with respect to grandchildren. No patient was retraced through an affected grandchild. Those female index patients (ten in all) who had had grandchildren happened to have had a high proportion of affected children (see table 1), but this is presumably a chance effect and much influenced by a female index patient who had three affected children, two of whom have in turn had children (figure). The total group of 34 women had affected children in a proportion similar to that in the whole original series of women.
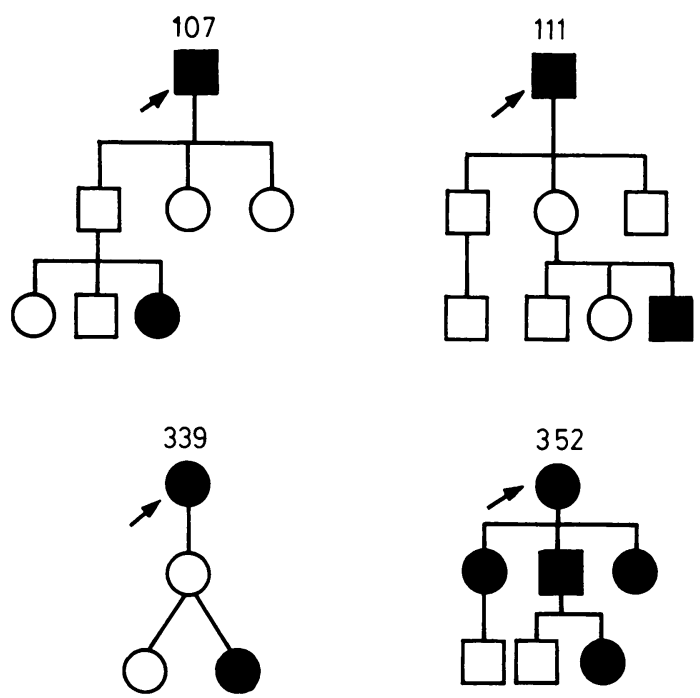

FIGURE Descendants of the four index patients who have an affected grandchild

\section{Results}

The findings on grandchildren are shown in the appendix with the original serial numbers of the index patients as in the earlier publication, ${ }^{1}$ and these findings are shown in tables $1 \mathrm{a}$ and $\mathrm{b}$ for male and female index patients, respectively, with distinction between unaffected and affected and by sex of child and grandchild.

In summary, of 138 grandchildren of index patients, four had pyloric stenosis confirmed at operation. Considering the grandchildren of male index patients, the proportion affected was 0 in 27 , 1 in 17,1 in 41 , and 0 in 35 for sons' sons, sons' daughters, daughters' sons, and daughters' daughters, respectively. Two affected grandchildren were born to unaffected children. For the grandchildren of female index patients the proportions affected were

TABLE 1a The grandchildren of male index patients (56), showing proportion affected

\begin{tabular}{|c|c|c|c|c|c|c|c|}
\hline \multicolumn{4}{|l|}{ Sons } & \multicolumn{4}{|l|}{ Daughters } \\
\hline Unaffected (27) & & Affected (3) & & Unaffected (45) & & Affected $(0)$ & \\
\hline $\begin{array}{l}\text { Sons } \\
0 / 25\end{array}$ & $\begin{array}{l}\text { Daughters } \\
1 / 14\end{array}$ & $\begin{array}{l}\text { Sons } \\
0 / 2\end{array}$ & $\begin{array}{l}\text { Daughters } \\
0 / 3\end{array}$ & $\begin{array}{l}\text { Sons } \\
1 / 41\end{array}$ & $\begin{array}{l}\text { Daughters } \\
0 / 35\end{array}$ & $\begin{array}{l}\text { Sons } \\
0 / 0\end{array}$ & $\begin{array}{l}\text { Daughters } \\
0 / 0\end{array}$ \\
\hline
\end{tabular}

TABLE 1b The grandchildren of female index patients (10), showing proportion affected

\begin{tabular}{|c|c|c|c|c|c|c|c|}
\hline \multicolumn{4}{|l|}{ Sons } & \multicolumn{4}{|c|}{ Daughters } \\
\hline \multicolumn{2}{|l|}{ Unaffected (3) } & \multicolumn{2}{|c|}{ Affected (3) } & \multicolumn{2}{|c|}{ Unaffected (6) } & \multicolumn{2}{|c|}{ Affected (1) } \\
\hline $\begin{array}{l}\text { Sons } \\
0 / 2\end{array}$ & $\begin{array}{l}\text { Daughters } \\
0 / 2\end{array}$ & $\begin{array}{l}\text { Sons } \\
0 / 3\end{array}$ & $\begin{array}{l}\text { Daughters } \\
1 / 1\end{array}$ & $\begin{array}{l}\text { Sons } \\
0 / 4\end{array}$ & $\begin{array}{l}\text { Daughters } \\
1 / 5\end{array}$ & $\begin{array}{l}\text { Sons } \\
0 / 1\end{array}$ & $\begin{array}{l}\text { Daughters } \\
0 / 0\end{array}$ \\
\hline
\end{tabular}


0 in 5,1 in 3,0 in 5 , and 1 in 5 , respectively. One affected granddaughter was born to an affected child, the other (a girl with a like-sex dizygotic twin) to an unaffected child.

\section{Discussion}

Though the numbers are small the influence of sex of index patient is seen even more strongly in the grandchildren than in the children. In the children, the risk was about three times greater where the index patient was female. In the grandchildren it is nearly seven times greater ( 2 in 18 as compared with 2 in 120). The proportion affected of the few grandchildren born so far to female index patients is as high as that of children (13\%), though one might expect that this high proportion will fall as the numbers increase. Of the few grandchildren born to an affected child of an index patient a higher proportion (1 in 10) are affected than of those born to an unaffected child ( 3 in 128). The pedigrees of the four families where an affected grandchild was born are shown in the figure and the serial number by which they can be identified in the original paper is also shown.

The information on grandchildren may be compared with that available in the original series ${ }^{1}$ on the two other types of second degree relatives, the maternal and paternal half-sibs and the nephews and nieces. The comparison is set out in table $2 \mathrm{a}$ and $b$.

Within the limits of chance variation resulting from small numbers, the proportion affected of grandchildren and half-sibs of each type is consistent with the proportion affected of nephews and nieces, except perhaps the high proportion affected of granddaughters of female index patients. Overall, for the male index patients the proportion of male second degree relatives affected is $2 \cdot 23 \%( \pm 0.78)$ and of the female second degree relatives $0.53 \%( \pm 0.38)$. For female index patients the proportions are $4.31 \%$ $( \pm 0 \cdot 19)$ and $1 \cdot 72 \%( \pm 1 \cdot 49)$, respectively. These are approximately $4 \frac{1}{2}, 5 \frac{1}{2}, 8 \frac{1}{2}$, and 17 times the birth frequency in the general population of the equivalent sex.

As regards the suggestion ${ }^{2-4}$ that the high risk to the children of female index patients might be the result, at least in part, of a maternal influence (Dodge ${ }^{2}$ suggested transplacental passage of gastrin) on the developing fetus, the best test is a comparison of the proportion affected of maternal and paternal half-sibs. Our limited data, shown in table 2a, show no significant difference, 1 in 47 affected compared with 1 in 61. A further, though less direct, test of a major maternal direct effect on the fetus in utero is given by grandchildren and also by

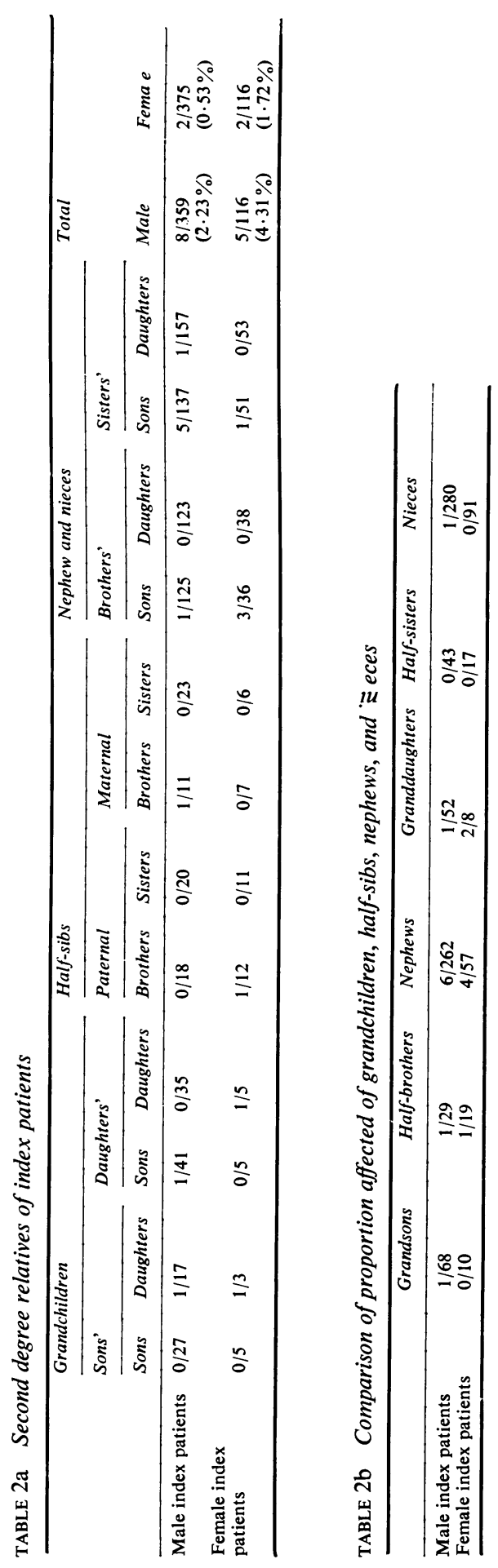


nephews and nieces. A woman and her daughter, and a woman and her sister, might share to some degree this tendency to have a direct intrauterine effect on the fetus, but a woman and her son and a woman and her brother could hardly do so. Therefore, the higher risk to sibs and children of female than of male index patients might also be seen in female index patients' daughters' and sisters' children, rather than in their sons' and brothers' children. Though the numbers of affected children are small the opposite is the case, the figures being 1 in 10 and 1 in 104, compared to 1 in 8 and 3 in 74 (table 2a).

\section{Addendum}

One female index patient, who had two sons and an affected daughter but no grandchildren when we ceased systematic collection in June 1979, has since had an affected grandson born to her affected daughter. But we do not yet have information on all grandchildren born since June 1979 .

\section{References}

1 Carter CO, Evans KA. Inheritance of congenital pyloric stenosis. J Med Genet 1969;6:233-54.

2 Dodge JA. Infantile pyloric stenosis: a multifactorial condition. Birth Defects 1972;VIII, No 2:15-21.

3 Kidd KK, Spence MA. Genetic analyses of pyloric stenosis suggesting a specific maternal effect. $J$ Med Genet 1976;13:290-4.

4 Carter CO. Genetics of infantile pyloric stenosis. Birth Defects 1972;VIII, No 2:12-4.

Requests for reprints to Professor C O Carter, MRC Clinical Genetics Unit, Institute of Child Health, 30 Guilford Street, London WC1N 1EH. 
The grandchildren of patients with pyloric stenosis

APPENDIX $R=$ Ramstedt's, $T=$ Pyloric tumour, but no operation

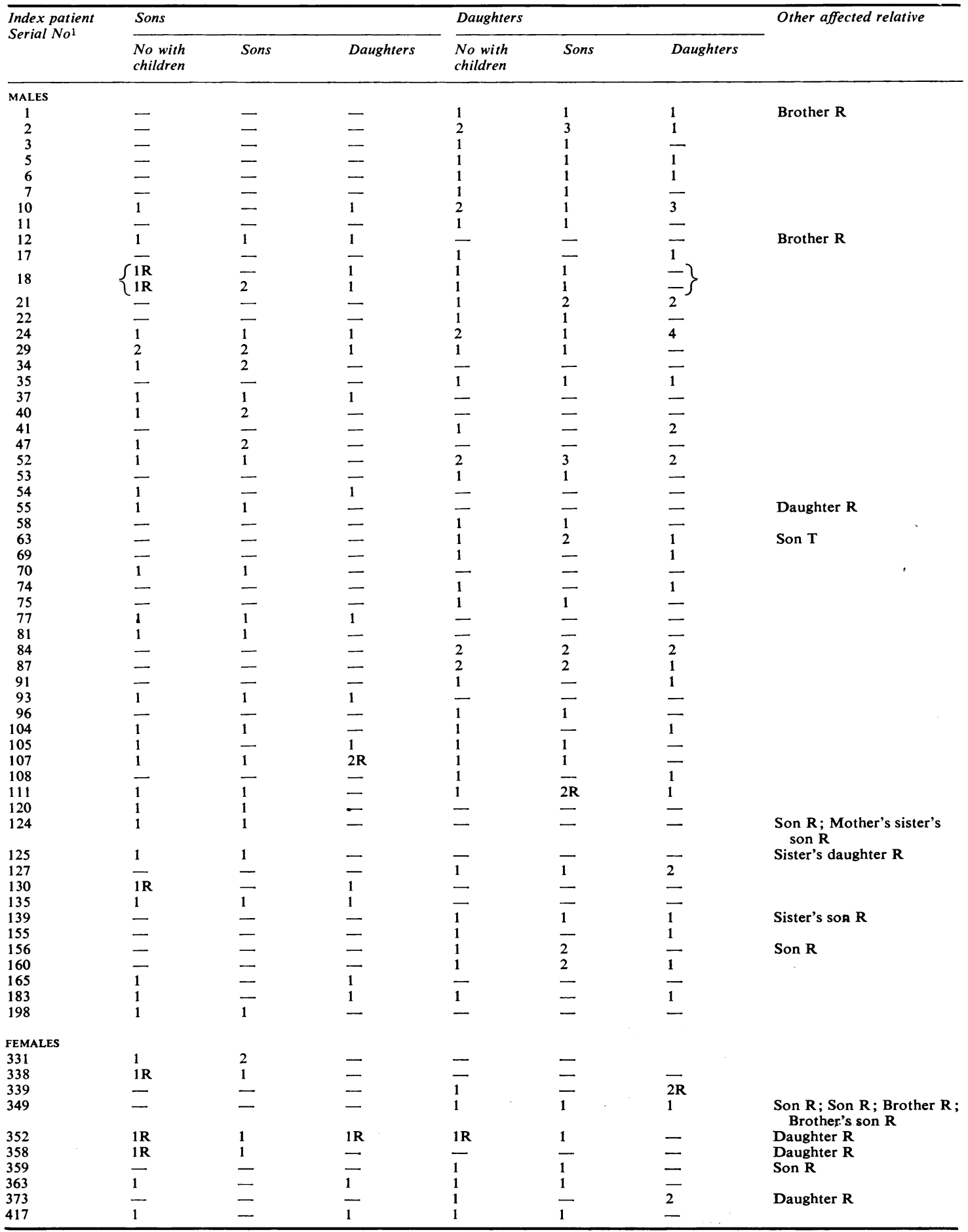
son $R$ Sister's daughter $\mathbf{R}$

Sister's son $\mathbf{R}$

Brother's son $R$

Daughter R

Son R

Daughter R 